of each packet displaying strong written and visual warnings about the hazards of smoking.

\section{Probity in public pronouncements}

The tobacco companies have an increasingly long record of being successfully prosecuted for misleading and deceptive behaviour under trade practices and consumer protection legislation. The Australian state of Tasmania has recognised that dealing with an entrenched pattern of such behaviour by case law and usually civil prosecution is an unsatisfactory way of curbing it. Instead, it has proscribed-and provided penalties for-issuing misleading public statements about either tobacco or the tobacco industry.

The film shot (from Die Another Day) is from the Kobal Collection.

Konrad Jamrozik is professor of primary care epidemiology, Imperial College, London, and visiting professor in public health, School of Population Health, University of Western Australia, Perth.

The ABC of smoking cessation is edited by John Britton, professor of epidemiology at the University of Nottingham in the division of epidemiology and public health at City Hospital, Nottingham. The series will be published as a book in the late spring.

\section{Key points}

- Effective tobacco control programmes should tackle smoking at the population level

- Health staff working in smoking cessation should know about the main population strategies

- All tobacco advertising, sponsorship, and product placement should be banned

- Smoke-free policies should operate in all public places and workplaces

- Governments should introduce progressive price increases through $\operatorname{tax}$

- Mass media public education programmes are an important strategy

- Effective policing of tobacco laws and smuggling is needed

- Appropriate cessation services should be available to all smokers wanting to quit

- Current inconsistent legislation on tobacco products and medicinal nicotine needs to be reformed

Competing interests: $\mathrm{KJ}$ received costs for travel and accommodation from SmithKlineBeecham to attend a meeting of the Australian Smoking Cessation Consortium that was convened by the drug company. See first article in this series (24 January 2004) for the series editor's competing interests.

BMJ 2004;328:759-62

\title{
Corrections and clarifications
}

\section{Interactive case report: Treatment of nausea and vomiting during pregnancy}

Two errors occurred in the first two articles in this three part series by Nicola Harker, Alan Montgomery, and Tom Fahey (31 January, p 276; 7 February p 337). In the first sentence of the first article ("presentation"), we wrongly said that the pregnant woman in the case report was primiparous, whereas in fact (as we revealed later in the text) she already had a 5 year old daughter. In the second article ("case progression") reference 5 was wrong; two references to the "measure yourself medical outcome profile" (MYMOP) should replace this:

5 Paterson C. Measuring outcomes in primary care: a patient generated measure, MYMOP, compared with the SF-36 health survey. BMJ 1996;312:1016-20.

Paterson C, Britten N. In pursuit of patient-centred outcomes: a qualitative evaluation of

MYMOP, measure yourself medical outcome profile. J Health Serv Res Policy 2000;5:27-36.

Sustained clinical efficacy of sulfadoxine-pyrimethamine for uncomplicated falciparum malaria in Malawi after 10 years as first line treatment:five year prospective study

The authors have alerted us to a wrong date in the last paragraph of the full (bmj.com) version of this paper by Christopher $\mathrm{V}$

Plowe and colleagues (6 March, pp 545-8).

Sulfadoxine-pyrimethamine was introduced in the

KwaZulu-Natal region of South Africa in 1988 (not 1998, as stated).

What the educators are saying

An electronic glitch in the electronic processing of this Learning in Practice page by Val Wass and Paul O’Neill (24 January, p 210) resulted in a rogue reference appearing after the final item (Professionalism needs to be more clearly understood).

\section{Simulation of medical emergencies improves patients' care} Readers of this summary in "This week in the BMJ" (31 January) relating to the paper "Clinical risk management in obstetrics: eclampsia drills" by Sarah Thompson and colleagues (pp 269-71) may have been misled by the word "evacuate," which inexplicably appeared in the second sentence. Thompson and colleagues reported on a fire drill programme, using on-site simulation, to identify deficiencies in the management of [not "to evacuate"] patients with eclampsia.

$A B C$ of Eyes

In our zeal to conform to our own house style, which limits authors to only one job title and workplace address each, we wrongly fused the two affiliations of one of the authors of this series of articles from the ABC of Eyes (3 January, pp 36-8; 10 January, pp 97-9; 17 January, pp 156-8). Professor P T Khaw is professor and consultant ophthalmic surgeon at Moorfields Eye Hospital and the Institute of Ophthalmology, University College London (not professor of ophthalmology at Moorfields Eye Hospital, as we stated).

Diastolic heart failure

We failed to notice a missing level of evidence in the table accompanying this editorial by Ramachandran S Vasan (BMJ 2003;327:1181-2). The level of evidence for using imaging to determine the ejection fraction in order to diagnose systolic heart failure should have been shown as level I (evidence from several, large, well conducted randomised controlled trials).

\section{Obituary of Derek Herbert Clarke}

Injudicious editing of this obituary resulted in an error (28 February, p 526). Derek Clarke was married three times, so Audrey is his third wife (not second, as we stated).

Officials warn of looming humanitarian crisis in Sudan In this world of continually changing national borders, it would be unwise to rely on an old atlas to draw up maps for publication. Yet this is what we inexplicably did for this news article by Peter Moszynski (21 February, p 424). In our map of northeast Africa we wrongly showed Ethiopia as having a border on the Red Sea; in fact, as Eritrea gained its independence from Ethiopia in 1993, this is no longer the case. The Zaire label was also wrong-that country has been known as the Democratic Republic of Congo since 1997. And still not content with our inaccuracies, we also managed to omit Saudi Arabia’s final "a." 